\title{
Merging a Remote Microscope and Virtual Worlds: Teaching Kingdom Plantae on Basic Education
}

\author{
http://dx.doi.org/10.3991/ijoe.v12i04.5095 \\ C. P. Antonio, J. P. C. Lima, J. B. M. Alves, J. B. Silva and J. P. S. Simão \\ Federal University of Santa Catarina, Araranguá, Brazil
}

\begin{abstract}
This paper presents an educational tool based on open source software and low cost hardware to supplement science teaching, merging concepts of remote experiment, virtual worlds and virtual learning environment. Using an avatar, students can move around in an enriched environment and access a remote microscope that enables visualization of plant parts and interaction with the available samples.
\end{abstract}

Index Terms-remote experiments; virtual world; science teaching.

\section{INTRODUCTION}

Given the need of teachers to encourage students, it is of utmost importance to use methodologies that allow them to learn at their own pace in more attractive environments and consistent with their reality. In this context, practical activities are essential to bring together students and scientific knowledge, to relate theory to practice. According to [1], the practical activities arouse students' curiosity and, based on this interest, generate knowledge construction. Laboratories are one of the ways that teachers can use to provide activities that students participate actively in disciplines such as science classes.

A problem faced by many educational institutions is the maintenance cost of laboratory facilities, especially in public schools. In order to overcome this shortage, many institutions have adopted remote experimentation laboratories as an alternative to meet the need of performing practical activities. According to [2] the laboratory activities in education are recognized for bringing real benefits to students and, in this sense, use of remote laboratories have been used in the disciplines of science and engineering, allowing the student to remotely access the real equipment and providing additional benefits for institutions.

Another issue that has been discussed recently involves improving learning outcomes presented by the use of remote labs. A factor that can enhance these results is the user interface used to put the lab activity in a context. 3D virtual worlds allow the creation of rich environments and customized activities, providing the user with additional information about the lab. [2]

The following topics will present some aspects about the research and development of a 3D virtual environment and a remote microscope, both applied to science subjects of basic education. This 3D virtual environment was customized with contents focused on morphology of angiosperms, where students, through their avatars, can move through a nature trail. Such environment presents several theoretical concepts that will be presented dynamically, either through videos, dialogues, quiz or other learning objects. After walking in the trail and interact with learning objects, students can access the remote experiment to strengthen the concepts learned.

\section{BACKGROUND}

\section{A. Remote laboratories}

Remote laboratories are facilities physically distant from the users, but reachable through a computer network to interact and control real instruments and devices [1]. Remote Experimentation consists in performing real experiments over the Internet, allowing access to them and the possibility of interaction with the running processes. In this case, students are physically distant from the remote lab, but they can interact and control instruments through web interfaces as if they were in a hands-on lab [3].

According to [4], the characteristics of access and manipulation of a common laboratory are attractive in science teaching. However, the usual alternatives are virtual laboratories or simulators that only return values and observations previously recorded. Furthermore, these laboratories do not demonstrate important aspects of a real application, such as natural factors involved in an experience.

The remote experimentation laboratories have virtual access, but their experiences are real. The remote experimentation laboratories present a realistic view which increases student's motivation for problem solving, as enable interaction with real processes, unlike the virtual laboratories carrying out the simulation of the processes [5].

\section{B. $3 D$ Virtual Worlds}

The use of $3 \mathrm{D}$ virtual worlds in teaching-learning process has been observed in recent studies. These immersive environments provide resources to create real environments with simulations and high interactivity [6]. They provide not only interaction with objects, but also with other users, exploring the same environment via avatars. The illusion of immersion is also supported by actions and behaviors similar to the real world [7].

Virtual world offers effective and desirable features for remote experiments' access, such as group collaboration [8]. These environments also offer multiples ways of communication and provide a better sense of presence in the learning process. The third dimension sense is useful 
to improve collaborative learning and to provide practical activities in places that it would not be possible [9].

\section{IMPLEMENTED PROTOTYPE}

Currently, a computational platform that consists of a $3 \mathrm{D}$ virtual world and a remote experiment is being made available in RExLab ${ }^{1}$. The remote experiment consists of a digital microscope that shows a number of items to be observed. The microscope's base contains a disc that can be rotated both clockwise and anti-clockwise according to commands sent via web, so alternating the materials that the microscope's lens will focus on. The prototype presented in this paper enables users to send commands and to access images captured by the microscope via a web browser or a 3D virtual Worlds. The 3D Virtual World client provides an enriched environment where users can move through and send commands to the remote experiment. A scheme is illustrated in the figure 1 .

For this project, the materials available in the experiment and the theme of the virtual environment are focused on the content of kingdom Plantae, which is taught in 7th year of science subjects. We chose the 7 th year of elementary education because, as the Basic Education Development Index (IDEB) indicates, this year is considered the main 'thermometer' of the quality of education. Generally, there is an improvement in the indicators for the first years of primary school. However, when we compare this first period to the next years, we find that indicators from 6th to 9 th year are almost stagnant, reflecting the poor preparation of students coming to high school [10].

The proposed environment is part of RExLab design based on the concepts of Mobile Remote Experimentation (MRE), so it follows the same architecture model. In this model Mobile Remote Experimentation (MRE), the Virtual Learning Environment (VLE) and the Educational Contents are developed.

\section{A. Computational platform}

The computational platform includes a server with a Linux operating system, data base management system, webserver application and PHP interpreter. We use the Moodle as virtual learning environment, and it provides the basis for all didactic material related to the experiment. To create the $3 \mathrm{D}$ virtual world, we use the OpenSim software, which is completely free, open source and a great alternative for the Second Life software. The platform also includes Sloodle software, which integrates the Moodle with OpenSim and provides learning tools that exists in Moodle, such as videos, slides, quizzes and questionnaires, available in the 3D Virtual World. Finally, the experiment is reachable by $3 \mathrm{D}$ virtual environment and web application, both in usual computers and mobile devices.

The architecture also includes the Virtual Learning Environment, Moodle, which is the basis for all Didactic Content, including theoretical and pedagogical part of the platform. After using the virtual world, we intend that the student go to the VLE, directly through the website or through the $3 \mathrm{D}$ virtual world, verify the concepts related to content covered by the discipline, as shown in the figure 2 .

${ }^{1}$ http://rexlab.ufsc.br

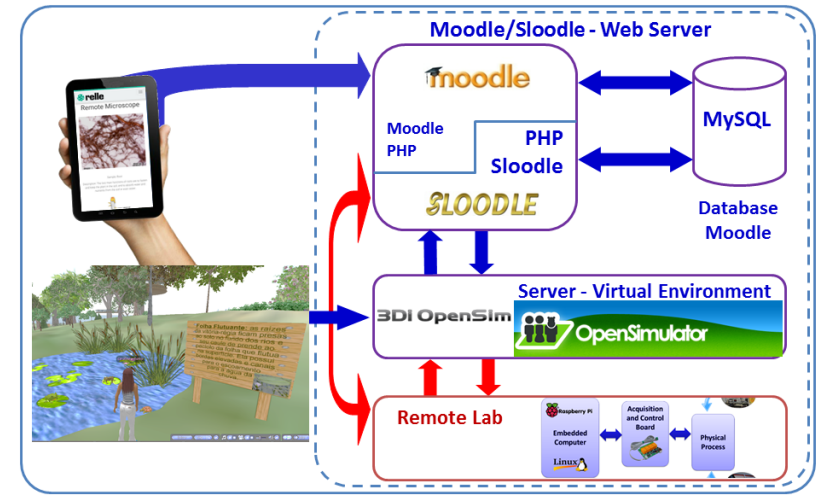

Figure 1. Proposed model of pilot project.

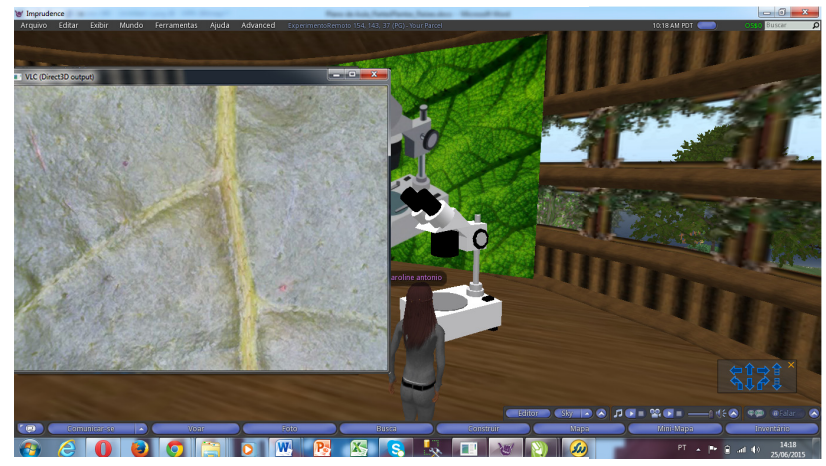

Figure 2. Snapshot of 3D Virtual World showing the access of a remote microscope through it.

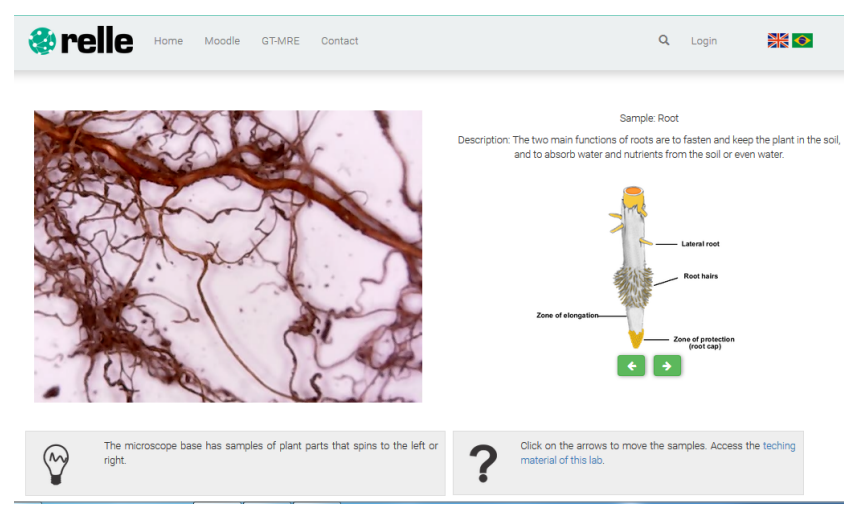

Figure 3. Screenshot of HTML5 client provided by RELLE.

Another part of our computational platform includes a server that hosts a remote lab management system, RELLE, available at http://relle.ufsc.br. In the figure 3 is shown the web browser interface, which is a HTML5 client with responsive design to manage and access the labs made available by RExLab.

\section{B. Pilot remote lab}

The pilot remote lab consists of a digital microscope that captures images zoomed in about 1000 times and a Raspberry Pi model $b^{+}$, as shown in the figure 4 . This board has lower price when compared to a conventional computer and has enough capacity to connect equipment to the Internet. Using VLC software, it streams images from the web camera to webpages and embed in virtual worlds.

Another board is used to drive a servomotor to move the disc that contains biological materials for analysis. This board is reachable through serial port and its function 
is also acquiring signals from sensors as well (position, displacement, etc.). There are reed switch sensors triggered by magnetic material that determine the stop position of each slot. The board used for controlling a servomotor and reed switch sensors was developed by RExLab's team, and it can be adjusted to include more sensors and actuators.

The remote microscope, as well as all the other labs, was developed following the architecture shown in the figure 4. The remote labs are located in Federal University of Santa Catarina, in the RExLab facilities. They are based on open hardware and open source software, and they differ mainly in sensor and actuators attached according to its work.

\section{CONCLUSION}

The remote experimentation laboratories emerged as an alternative to lack of laboratories in educational institutions. Students who previously had not the opportunity to undertake practical activities and see reactions when they interfere in its operating conditions may now have this opportunity by using this type of laboratory.

The 3D virtual worlds allow the creation of parallel world without limits to creativity and possibilities. It supports the creation of all types of environment where the student can interact through their avatars, either shaped like an educational game or by analogy to classrooms. It is possible to create an immersive and engaging environment for the student using virtual worlds, where they can learn about contents of different subjects.

The combination of virtual worlds with remote experimentation can create an immersive and attractive environment for students, promoting learning through the interaction and experimentation. In addition, the possibility of access via mobile devices expands the possibilities of use, making it easier for students to use not only in the classroom, but wherever they want with an internet connection.

\section{REFERENCES}

[1] A.M. Maiato, Neurociências e aprendizagem: O papel da experimentação no ensino de ciências [Neurosciences and learning: the role of the experimentation in science education], master's thesis, Universidade Federal do Rio Grande. Rio Grande, 2013.

[2] T. Machet and D. Lowe, "Issues integrating remote laboratories into virtual worlds," in Proc. of the 30th ascilite conference, 2013.

[3] R. Marcelino et al, "Virtual 3D Worlds and Remote Experimentation: a Methodology Proposal Applied to Engeneering Students". In: UNIVERSITY OF DEUSTO (Espanha). Using Remote Labs in Education:Two Little Ducks in Remote Experimentation. Bilbao. 2011. Cap. 17. p. 349-374.

[4] J. Silva et al, "Mobile Remote Experimentation applied to Education". In: UNIVERSITY OF DEUSTO (Espanha). IT Innovative Practices in Secondary Schools: Remote Experiments. Bilbao. 2013. Cap. 11. p. 281-302.

[5] J. Traxler, "Mobile Learning: It's here but what is it?", http://www2.warwick.ac.uk/services/cap/resources/interactions/arc hive/issue25/traxler/ (current Aug. 30, 2007).

[6] M.J. Callaghan et al. "Hybrid Remote/Virtual Laboratories with Virtual”. In: REV 2010, Stockholm, 2010, v. 115, pp. 1-8. CDROM.

[7] M. Mine, "Virtual environment interaction techniques," UNC Chapel Hill computer science technical report TR95-018, pp. 507248-2, 1995.

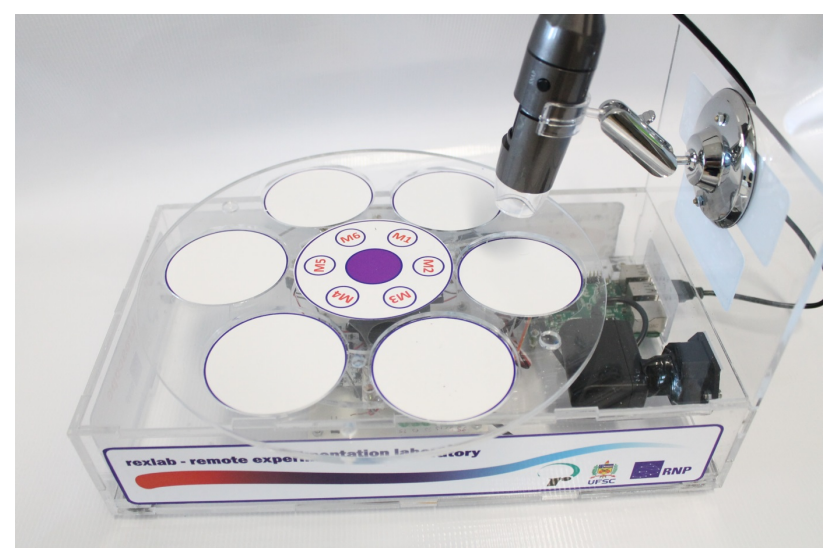

Figure 4. Remote microscope lab.

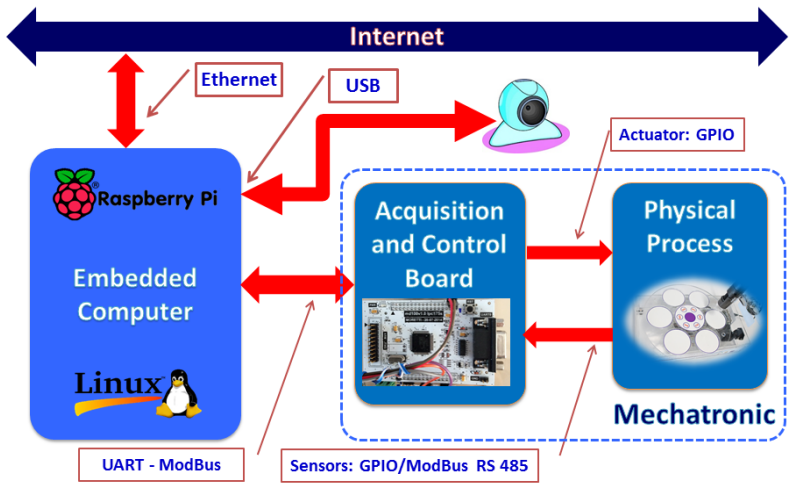

Figure 5. Block diagram of remote lab architecture used by RExLab.

[8] B. Dalgarno and M. J. Lee, "What are the learning affordances of 3-D virtual environments?," British Journal of Educational Technology, vol. 41, pp. 10-32, 2010. http://dx.doi.org/10.1111/j.14678535.2009.01038.x

[9] B. Scheucher, P. H. Bailey, C. Gütl, and J. V. Harward, "Collaborative Virtual 3D Environment for Internet-Accessible Physics Experiments," iJOE, vol. 5, pp. 65-71, 2009.

[10] INEP, Ideb 2013 Indica Melhora no Ensino Fundamental [Ideb 2013 indicates improvement in basic education], http://portal.inep.gov.br/web/portal-ideb (current Sept. 17, 2014).

\section{AUTHORS}

C. P. Antonio is a master student at PPGTIC/UFSC and teacher at the Lutheran University of Brazil (Ulbra). (e-mail: caroline.antonio@posgrad.ufsc.br).

J. P. C. Lima is an academic at the Federal University of Santa Catarina, Araranguá, Brazil. (e-mail: joao.pcl@ufsc.br).

J. B. M. Alves is professor at the Federal University of Santa Catarina, Araranguá, Brazil. (e-mail: jbosco@inf.ufsc.br).

J. B. Silva is professor at the Federal University of Santa Catarina, Araranguá, Brazil. (e-mail: juarez.silva@ufsc.br).

J. P. S. Simão is an academic at the Federal University of Santa Catarina, Araranguá, Brazil. (e-mail: josepedrosimao@gmail.com).

This work was supported in part by Coordination for the Improvement of Higher Education Personnel (CAPES).

Submitted 27 September 2015. Published as resubmitted by the authors on 27 November 2015. 